\title{
College Physical Education Course Management System Based on Internet of Things
}

\author{
Yu Ding, ${ }^{1}$ Nian Zhang, ${ }^{2}$ and Yupeng $L i \mathbb{D}^{1}$ \\ ${ }^{1}$ College of Physical Education and Health, Linyi University, Linyi 276000, Shandong, China \\ ${ }^{2}$ Capital University of Physical Education and Sports, Beijing 100191, China
}

Correspondence should be addressed to Yupeng Li; liyupengty@lyu.edu.cn

Received 30 April 2021; Revised 21 May 2021; Accepted 31 May 2021; Published 19 June 2021

Academic Editor: Sang-Bing Tsai

Copyright $\odot 2021$ Yu Ding et al. This is an open access article distributed under the Creative Commons Attribution License, which permits unrestricted use, distribution, and reproduction in any medium, provided the original work is properly cited.

With the continuous development of the Internet of Things technology, the latest information technology represented by the network, digital, and intelligence is changing people's work, learning, and lifestyle and bringing new development space to education. The physical education curriculum management system in colleges and universities brings convenience to teachers and students, facilitates the centralized management of students by teachers, ensures the safety of students in physical education classes, and reduces the risk of injury to students in physical education classes. The innovative construction of college physical education curriculum is a systematic project, which aims to deepen educational reform, improve the physical condition of students, and enable students to experience advanced teaching methods. At the same time, university physical education teachers have a degree of higher education, provide information, and promote interaction with students. This improves the quality and ability of teachers and students themselves. The paper proposes related research on the design of college physical education curriculum management system based on the Internet of Things. Through the use of Internet of Things wireless channel technology and UWB indoor positioning technology, combined with the impact of the Internet of Things on cognition, the arrangement of physical education courses and student positioning and sign-in are designed, and the results of the system test are found. Compared with the previous system,. this system has improved the positioning and sign-in accuracy of physical education courses by $5-10 \%$, and the efficiency of physical education courses has also increased by $2-5 \%$.

\section{Introduction}

1.1. Background. The Internet of Things is a technology based on the development of the Internet, communication technology, and network telecommunications. It can link connected communication equipment and electronic equipment and connect related equipment through a wireless network. The controller can remotely control the equipment and issue commands, completing the instructions. In the Internet of Things, real objects are classified into electronic tags for online connection, and the specific location of each object is controlled by the Internet of Things.

1.2. Significance. The functional requirements of physical education curriculum management in colleges and universities today are very complicated. The generation of optional classes, the statistics of extracurricular physical exercises, the composition of physical fitness scores, the management of the final natural class teaching scores, the statistics and analysis of test scores, and physical fitness work of reporting to the country have become extremely cumbersome. These management requirements can no longer be achieved by simple document management. At the same time, these cannot be integrated with school educational administration. The school only needs to teach classes and grades. As for other requirements, it is beyond the scope of school management and so the development of an independent sports management system and the more urgent construction of functions. Designing a sports curriculum management system can reduce the teaching burden of teachers and reduce the waste of related sports resources.

1.3. Related Work. In the past decade, product service system (PSS) design has received extensive attention and is expected to be affected by the rapidly growing application of 
IoT technology. The research of Shih et al. proposes a sixstep design method by expanding the visual mapping design method of PSS using IoT technology, and designers can use the suggested method to select products with higher customer value in the design of product service systems (appropriate application of IoT technology) [1]. However, their research based on the Internet of Things technology is only limited to the product service system, and the system of course management has not been innovated and explored. In the homework management of accounting courses, the results of Fratto et al.'s research show that, compared with traditional paper and paper homework, the use of online homework management system is effective in improving student performance and course satisfaction in introductory accounting courses [2]. But they only managed and researched online homework. They have not thought about and delved into accounting or sports-related course management. Technical developers such as Yeo aim to develop a course monitoring system by students and evaluate the course quality management system (CQMS) implemented as an educational evaluation tool [3]. Their research is based on the ADDIE model, which is a well-known instructional design model. The ADDIE process includes needs analysis, course monitoring and course evaluation design, evaluation form development, course monitoring implementation, and plan evaluation. In order to meet the needs of a system that can replace traditional classroom assessment methods, their research has developed and implemented a new curriculum assessment system [4]. Compared with quantitative evaluation methods, student course monitoring provides more qualitative information about courses and courses from a student's perspective. The student's realistic description helps to understand how the student feels the classroom atmosphere and what kind of teaching style the student likes. However, some people think that only through the above assessment methods, students cannot reliably and effectively choose the teachers they like, and the teaching design model of ADDIE is not suitable for the management of physical education courses in colleges and universities.

1.4. Innovation. The use of Internet of Things technology to design a college sports curriculum management system not only guarantees the privacy and security of teachers and students' personal information but also allows college sports curriculum resources to be fully utilized. Traditional sports network course management systems are mostly constructed with static databases and static resources. However, based on the Internet of Things environment, the sports course management system directly faces the actual sports course teaching and realizes the collection and storage of real-time data in the classroom. Applying the concept of the Internet of Things in the field of physical education curriculum management can give this field more "intelligent" elements to complete the mutual exchange and collaboration of physical education curriculum data. Based on the technology of the Internet of Things, this paper uses the intelligent management of college physical education courses as the research carrier and develops a management system based on physical education courses, which provides a new attempt to realize the use of advanced information methods to assist physical education.

\section{Description of Methods and Related Concepts}

2.1. IoT Wireless Communication Technology. The cost of wireless communication technology is cheap, the construction period is short, the adaptability and scalability are relatively good, and the communication equipment is easier to maintain. The following are several common communication models $[5,6]$.

2.1.1. Friesian Free Space Propagation Model. Assuming that the wireless signal transmission power is $P x$ and the transmitting antenna radiates uniformly in all directions, the power per unit area on the sphere with a distance of $d$ from the transmitting source is

$$
S=\frac{P_{c}}{4 \pi d^{2}}
$$

Since the antenna has directivity, suppose the gain of the transmitting antenna is $G c$ and the effective area of the receiving antenna is $B$; then, the power intercepted by the receiving antenna is

$$
P_{e}=\frac{B G_{c} P_{c}}{4 \pi d^{2}}
$$

The effective area of the antenna $B$ is

$$
B=\frac{G_{e} \lambda^{2}}{4 \pi}
$$

where $G e$ is the gain of the receiving antenna and $\lambda$ is the free-space wavelength. Substituting the $P e$ formula into the Friis equation:

$$
\frac{P_{e}}{P_{c}}=G_{c} G_{e}\left(\frac{\lambda}{4 \pi d}\right)^{2} .
$$

It can be seen from the above formula that when $G c, G e$, and wavelength $\lambda$ are determined, the propagation distance of the radio signal can be calculated from the signal strength received by the reader [7].

2.1.2. Logarithmic Path Loss Model. In practice, in order to facilitate the estimation of the distance between the sender and the receiver, the following large-scale propagation model is often used:

$$
P L(d)=P L\left(d_{0}\right)+10 n \lg \left(\frac{d}{d_{0}}\right)+X_{\sigma}(d B) .
$$

If $P_{e}(d)$ is the signal strength (RSSI) received by the receiving end when the distance between the receiving end and the transmitting end is $d$, then

$$
P_{e}(d)=P_{c}-P L\left(d_{0}\right)-10 n \lg \left(\frac{d}{d_{0}}\right)+X_{\sigma}(d B) .
$$


2.2. IoT UWB Positioning Technology. The UWB positioning method is to use a time stamp generated by each module [8]. The time stamps are independent of each other and will be generated as soon as the module is started. The calculation formula is shown in

$$
S=C x[(t a 2-t a 1)-(t b 2-t b 1)] .
$$

The TW-TOF ranging method mainly calculates the distance between two nodes by the time the signal propagates between two asynchronous transceivers, which is a two-way ranging technology. The calculation process is as shown in

$$
\text { TTOF }=\frac{(\text { TTOT }- \text { TTAT })}{2} .
$$

The distance between two points can be calculated based on the product of TTOF and electromagnetic wave propagation velocity $(C)$ :

$$
D=C * \text { TTOF. }
$$

UWB positioning technology has a short working time and has low power consumption requirements for system equipment, and the signal interference of other equipment is relatively small [9]. In addition, there are many tags that can work at the same time within 1 second, and the capacity is high, which is suitable for the course management system with a large number of users and the location check-in of students $[10,11]$.

2.3. Evaluation Criteria for Indoor Positioning Accuracy Based on Internet of Things Technology. The following are several error evaluation standards for indoor positioning technology based on the Internet of Things technology.

2.3.1. Mean Square Error (MSE). In the two-dimensional indoor positioning estimation, the mean square error (MSE) is

$$
\mathrm{MSE}=E\left[\left(x_{1}-x_{0}\right)^{2}+\left(x_{1}-x_{0}\right)^{2}\right]
$$

In practical applications, the square root of the mean square error-standard error (RMSE) is often used to describe the measurement and estimation situation:

$$
\operatorname{RMSE}=\sqrt{E\left[\left(x_{1}-x_{0}\right)^{2}+\left(y_{1}-y_{0}\right)^{2}\right]} .
$$

2.3.2. Circle/Sphere Error Probability (CEP). The circle/ sphere probability error (CEP) is a simple and strict measure of estimation accuracy, which describes the uncertainty of the estimation result relative to its mean value [12]. The main formula is shown in

$$
\mathrm{CEP} \approx \sqrt{\sigma_{x}^{2}+\sigma_{y}^{2}}
$$

The realization process of the complex function of the error probability is shown in Figure 1.

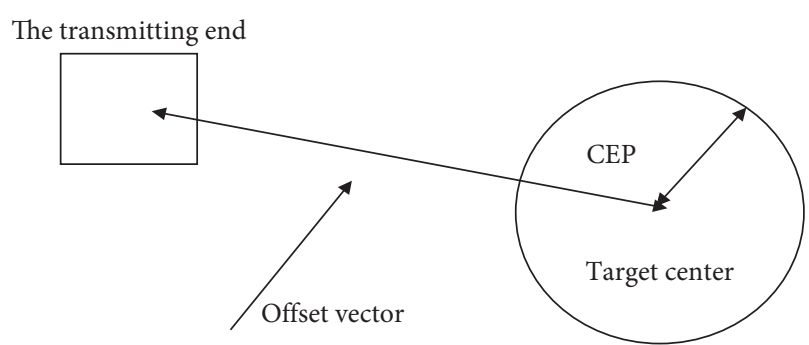

FIgURE 1: Realization diagram of circular error probability.

2.3.3. Estimated Error (EE). The estimation error is the most commonly used method among the three error estimation methods, which can be expressed as

$$
\mathrm{EE}=\sqrt{\left(x_{1}-x_{0}\right)^{2}+\left(y_{1}-y_{0}\right)^{2}}
$$

2.4. Cost Function Formula. The cost function formula is shown in

$$
C=\sum \omega i V i
$$

Among them, $\mathrm{C}$ represents the cost function value, $\omega_{i}$ represents the weight of the $i$-th parameter, and $V_{i}$ represents the $i$-th parameter involved in the operation. Equation (14) is a general expression of the cost function [13]. In practical applications, in order to make the curve describing the cost function smoother, the cost function is usually as shown in

$$
C=\sum \omega_{i} * \ln V_{i}
$$

\subsection{The Impact of the Internet of Things on Cognition}

2.5.1. Technical Cognition of Informatization and Intelligence. The creation of technology is mainly to adapt, simulate, and optimize the corresponding structure and function of the human brain and sensory organs. The discussion of cognitive mechanisms will mainly adopt the "element-process" analysis model; that is, the core element of technological cognition is information and data resources $[14,15]$. The main process is the information reading, transmission, storage, calculation, feedback application, and other links. Among them, the sensing technology (such as RFID, EPC, and QR) corresponding to the reading and transmission link realizes the data transmission and reading between objects [16]. The storage and computing links correspond to databases, cloud computing, communications, automation, etc.; the feedback and application links correspond to methods and concepts such as quantitative control and system coordination. Technical cognition is the objective processing of subjective mental activities, that is, the reconstruction of subject cognition through objective technical forms and the realization of corresponding functions. Consciousness, perception, and cognitive functions will not be exclusive to humans [17]. Cognitive problems will be transformed into problems of intelligent 
processing of information through the effects of technical means. Objects can work with humans to think under the control of specific programs and instructions to generate consciousness, that is, realize artificial intelligence or machine learning. Can the interaction mechanism and process between "environment-human brain-body" be achieved by relying on technical means? Through comparative analysis, the cognitive process of the human brain includes first receiving and translating external information, and establishing the corresponding relationship between the human body's sensory organs and the human brain, while the cognitive process of the machine and artificial intelligence system is translating and transmitting information and data, then builds relationship through the sensor. The sensor uses the corresponding program, logic, algorithm, function, etc. to establish the corresponding relationship, relying on the support of database, cloud computing, and other technical forms, and finally is operated by the mechanical structure, such as the actuator, transmission mechanism, power supply, and other physical hardware to complete the whole process. The control process is the complete form of technological cognition [18]. The main factors in the two processes are information and data. In the process of interaction and cognition, it is the processing of information, that is, the processing links of information production, transformation, transmission, storage, and calculation. Inspired by the form of the Internet of Things technology to analyze and discuss from the perspective of information, in turn, it can also use information technology or means to improve cognition and control, that is, the optimization of cognitive accuracy, efficiency, quality, etc. Through the above analysis, looking at traditional philosophical issues from the perspective of informatization and intelligent technology is based on objective conditions and the environment, that is, the source of information, using corresponding physical methods and principles, and based on the concept and design concept of the Internet of Things technology, trying to find an appropriate technical models to interpret cognitive issues [19]. The production and operation mode of the form of the Internet of Things technology can adapt to the cognitive mechanism of human beings [20]. The two processes have common points and intersections and can be used for mutual analysis and interpretation. The new technological form created by the design concept of the Internet of Things will be cognitive and intelligent; that is, in terms of structure and function, it conforms to the mode of the subject's reflection and understanding of the object. Therefore, it brings new inspiration and thinking to the analysis and discussion of traditional epistemology [21, 22]. The comprehensive interaction system between the outside world and the human brain and body is the result of the interaction with itself and the outside world under the condition of the occurrence of cognitive mechanisms [23]. The perception and cognition between things-things and people-things will be realized based on the human brain's understanding and cognition of the outside world. It is precisely because of the exploration and analysis of the human brain's cognitive mechanism and the artificial intelligence system created by technical means. It can be well adapted to the generation mechanism and process of human brain cognition. From this perspective, the theoretical core of the technology is all cognitive problems. It is based on the knowledge and understanding of human brain or body functions. Create corresponding technologies to adapt and optimize the functions of the human brain and body. In short, the process of technological creation is also the process of cognitive practice. The intelligent cognition characteristics embodied in the technology system of the Internet of Things obtain basic attribute information from objective things and create brand-new information through processing or reproduction. The essence of data mining, identification, and reading is the process of informatization; that is, the process of transforming from physical reality to virtual information makes things transformed into informationized things through technical means, and the process of obtaining material and energy will be transformed into the production, flow, processing, and application of corresponding information. The process, that is, the translation mode between "things and letters", is constructed: AA'. This kind of informatization model will have important significance [24]. First, it can transform from the traditional thinking concept of the possession and utilization of material and energy resources to the grasp and control of information resources; second, the cost and efficiency of information circulation will change. It is much better than logistics and energy flow. Third, it can use the information network platform (Internet) to establish a material-related network to achieve more precise and efficient control goals [25].

\subsubsection{Design Concept of Technological Cognitive Form.} Although the Internet of Things (IOT) is the Internet of things-things, the apparent thing-things connection is still based on information interconnection, and objects are identified and read through the form of sensing technology (such as radio frequency technology RFID) [26]. Take the attribute information of objects and participate in the production, translation, circulation, and other links of data, rely on the information interconnection platform to connect everything in the world, process information by technical means, and establish connections between objects through the network, so as to achieve technical cognition. The passage between the virtual information world and the real physical world is thus opened. The integration of the two spaces can be widely used, which means that there may be more development opportunities and potential spaces in design concepts, technological innovations, and business models $[27,28]$. The Internet of Things technology realizes the "interactive dialogue" between things to a certain extent, which is different from the traditional way and process of human cognition and understanding of things. The Internet of Things technology (mainly taking RFID as an example) can reflect physical attributes. The characteristic information is made into an electronic product label (EPC), which is built-in or attached to the surface of the object through a special sensing and reading device. On the one hand, it can read the information and data reflecting the object; on the other hand, it can receive and sense, extract the information 
contained in other objects (such as two-dimensional code technology), and then realize the flow and transmission of information and data between objects [29]. The interaction process between objects is not only the human brain's comprehensive perception of objects, that is, through the comprehensive analysis and judgment of the brain and nervous system, the corresponding memory or impression is formed, and then the characteristics of the object are macroscopically analyzed and predicted. This is based on the human brain nervous system. The dominant process and method of cognition is the cognitive process of active perception, memory, analysis, and understanding of objects carrying attribute information through sensing and mutual induction equipment.

\section{Design and Development Experiment of College Physical Education Curriculum Management System}

3.1. Overall System Architecture. The overall goal of the development of this system is to design and develop a multifunctional college sports curriculum management system based on the knowledge and technical framework of the knowledge and technology that you have mastered, based on the indoor and outdoor positioning technology of the Internet of things and wireless signal channel technology. The architecture diagram is shown in Figure 2.

3.2. Function Analysis of Each Module of the System. After the system demand analysis, the system is finally divided into 3 functional modules, including college student personal center module, college teacher management course module, and system administrator module. The detailed system module frame diagram is shown in Figure 3.

Student module: the main function of the student module is to help college students choose their favorite physical education courses. Each college student must choose four different physical education courses during the four years of university and can only choose one physical education class each semester. In addition, students can also modify their own personal information, such as height, weight, personal avatar, motto. After choosing a physical education class to study, 5 minutes before the start of the weekly physical education class, you also need to position the sign-in according to the classroom sign-in initiated by the physical education teacher. The specific implementation framework of this module is shown in Figure 4.

3.2.1. Teacher Module. The main function of the teacher module is to help college physical education teachers in course management, allowing teachers to schedule and adjust courses. Under the premise of the Internet of Things, the arrangement of college physical education courses should not cause the time conflict between teachers and students. For example, the same teacher cannot take two physical education classes at the same time, the same student cannot take two classes at the same time, and the same student does not have more than 2 hours of physical education class per week. After the sports final exam at the end of the semester, the teacher can also input the sports scores of each student into this system, so that students can check their sports scores in time.

3.2.2. Administrator Module. The main function of the administrator module is to allow the system administrator to be responsible for the maintenance of the information stored in the database, to prevent the loss and leakage of user information and data of teachers and students, and to update and enter the latest physical education curriculum resources in a timely manner. Add and delete with teacher users. If there is a new teacher, you can add related teacher information. If there are teachers who resigned or transferred to other schools, you can delete teacher information.

\subsection{System Data Requirements and the Design of Related Data Tables in the Database}

\subsubsection{Data Requirements for College Physical Education Curriculum Management}

(1) Reliable Input and Processing of Data. It is necessary to ensure the accurate input of system data, which is a prerequisite for the administrator to operate and control this system; otherwise, the design of this platform system will be meaningless.

(2) Data Consistency and Integrity. For input data, a consistency rule needs to be set for this. If the integrity constraint cannot be met, the site must discard the data. At the same time, in order to ensure the integrity of the data, it is necessary to prevent data leakage and loss due to improper operation.

(3) Data Disclosure and Data Independence. The selection results of the entire physical education curriculum management system can be read and viewed by students. However, we have very little contact with cryptography. It is difficult to ensure the security of user information and data with the technology we know. Therefore, it is necessary to ensure that the security design of each module function of this sports course management system is relatively complete. Since then, it can also reduce hackers' intrusion into websites.

3.3.2. The Design of Relevant Data Tables for College Physical Education Curriculum Management. A good database design and concise SQL statement can make the college sports course selection system easier to complete. At the same time, the system can run very quickly. On the contrary, the disorganized data table will reduce the efficiency of the design system and will affect the storage and update of the data. Therefore, the database table design should comply with the following rules.

(1) Primary key constraints: all values in the table are required to be unique, and no empty values are allowed in the column. The system has established a primary key constraint for each table to ensure the uniqueness of each row. 


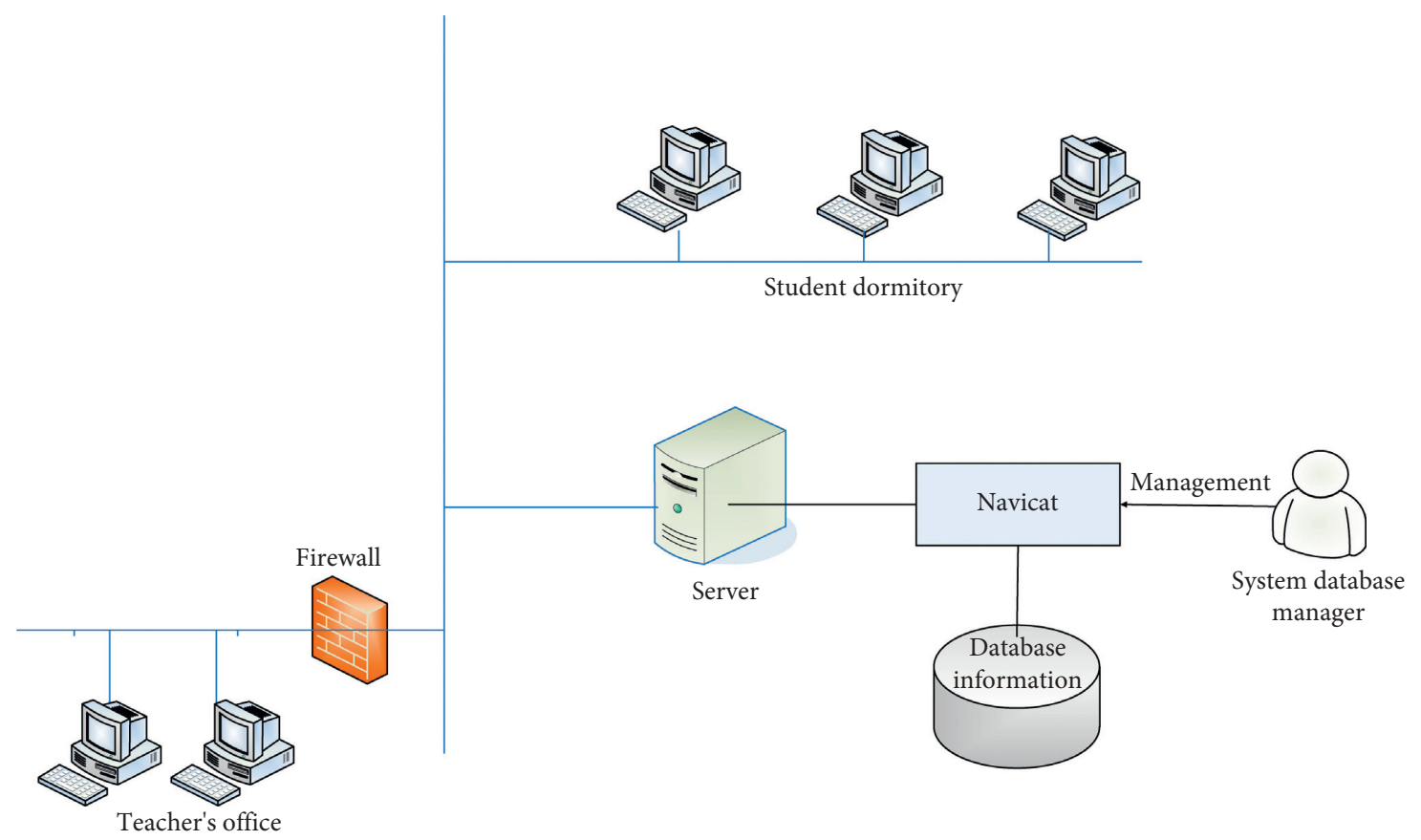

FIgURE 2: The overall architecture of the system.

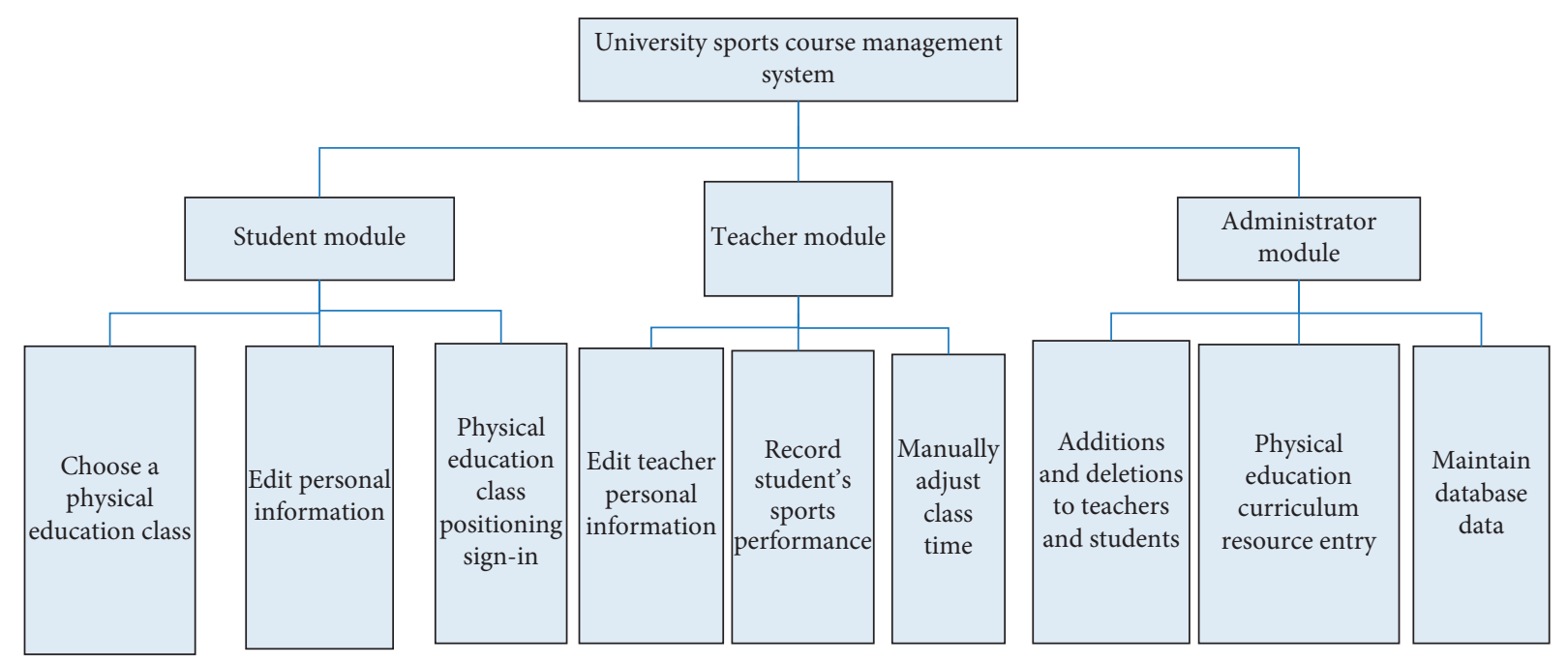

FIGURE 3: Frame diagram between the various modules of the system.

(2) Uniqueness constraint: all nonempty values in each column of the table are required to be unique, and only one empty value is allowed. In the physical design, the system uses a unique index for each table, to ensure that no two rows of the same record appear in the table.

(3) Foreign key constraints: it is a constraint relationship established between table fields or between two table fields. The database design of this system uses foreign key constraints in many places to prevent "dirty" data from appearing in the application table, and the application table to delete or update the referenced data at will.

(4) Default refers to the value inserted into the column by the database when the user does not explicitly enter a value. 


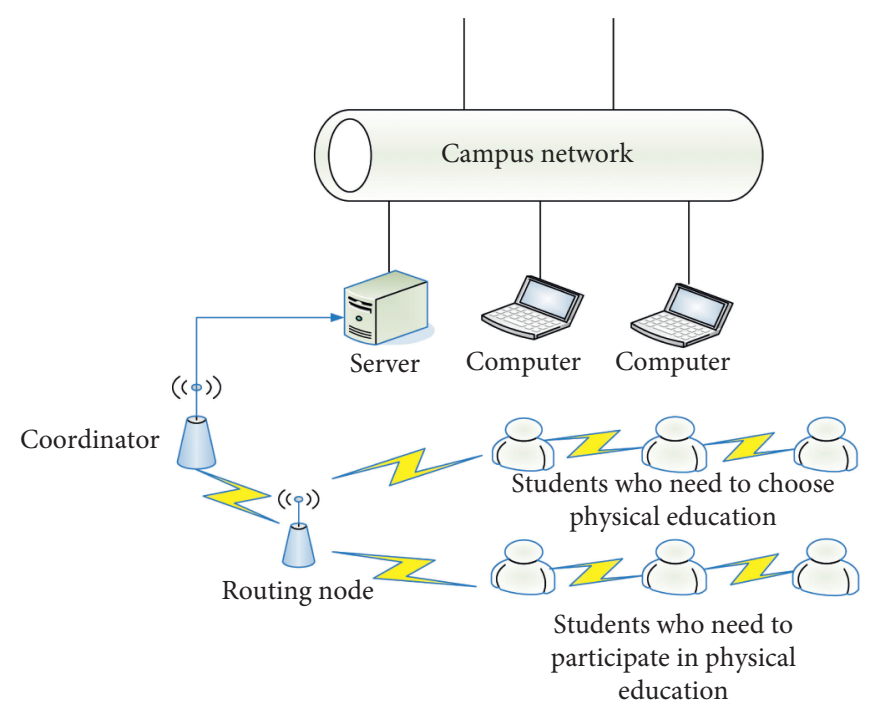

Figure 4: The frame diagram of the student module of the system.

The following is the detailed data design table of this system.

The physical education class description table mainly saves information such as the name of the physical education curriculum, the relevant information of teachers and students, and the time and location of the physical education curriculum. The specific information is shown in Table 1.

The physical education teacher information table mainly stores the basic information of the teacher, such as the teacher's name, password, and home address. The specific information is shown in Table 2:

The student table mainly saves the basic information of the student, such as the student's name, password, and class and whether or not they are in school. The table contains fields such as student ID, password, gender, and physical education class. The specific information is shown in Table 3.

The administrator information table mainly stores the personal information of the administrator and the information of teachers and students, such as the name, password, and home address of the administrator. The specific information is shown in Table 4.

\section{System Simulation Experiment and System Performance Analysis}

4.1. College Physical Education Curriculum Schedule. After completing the overall design of the experiment and the analysis of the functional module requirements, we conducted a simulation experiment on the college physical education curriculum management system in the next few months. We invited 50 physical education teachers from a certain university. Civil engineering students come from four different grades. The total number is 600 , of which half are boys and girls, using the college physical education curriculum management system based on the Internet of Things designed in this paper for testing. The development environment and development tools of the college physical
TABle 1: Class description table for physical education courses.

\begin{tabular}{lccc}
\hline Field name & $\begin{array}{c}\text { Data type } \\
\text { (length) }\end{array}$ & $\begin{array}{c}\text { Can it be } \\
\text { available }\end{array}$ & Remarks \\
\hline PE_ID & Char [20] & No & $\begin{array}{c}\text { Primary } \\
\text { key } \\
\text { Foreign } \\
\text { key }\end{array}$ \\
PE_STD_ClassID & Char [20] & No & Yes \\
PE_Location & Char [20] & No & $\begin{array}{c}\text { Foreign } \\
\text { key }\end{array}$ \\
PE_TEA_ID & Char [20] & Yes & \\
PE_Time & Char [20] & &
\end{tabular}

TABLe 2: Physical education teacher information table.

\begin{tabular}{lccc}
\hline Field name & $\begin{array}{c}\text { Data type } \\
\text { (length) }\end{array}$ & $\begin{array}{c}\text { Can it be } \\
\text { available }\end{array}$ & Remarks \\
\hline TEA_ID & Char [20] & No & $\begin{array}{c}\text { Primary } \\
\text { key }\end{array}$ \\
TEA_STD_ID & Char [20] & No & Foreign key \\
TEA_Sex & Char [4] & Yes & \\
TEA_Address & Char [20] & Yes & \\
TEA_Email & Char[50] & Yes & \\
TEA_Tel & Char [20] & Yes & \\
\hline
\end{tabular}

TABLE 3: Student table.

\begin{tabular}{lccc}
\hline Field name & $\begin{array}{c}\text { Data type } \\
\text { (length) }\end{array}$ & $\begin{array}{c}\text { Can it be } \\
\text { available }\end{array}$ & Remarks \\
\hline STD_ID & Char [20] & No & $\begin{array}{c}\text { Primary } \\
\text { key }\end{array}$ \\
STD_Pwd & Char [20] & No & \\
STD_Sex & Char [4] & Yes & Foreign key \\
STD_ClassID & Int & No & \\
STD_Email & Char[50] & Yes & \\
STD_Tel & Char [20] & Yes & \\
\hline
\end{tabular}


TABLE 4: Administrator information table.

\begin{tabular}{lccc}
\hline Field name & $\begin{array}{c}\text { Data type } \\
\text { (length) }\end{array}$ & $\begin{array}{c}\text { Can it be } \\
\text { available }\end{array}$ & Remarks \\
\hline ADM_ID & Char [20] & No & $\begin{array}{c}\text { Primary } \\
\text { key }\end{array}$ \\
ADM_Pwd & Char [20] & No & Foreign key \\
ADM_TEA_ID & Char [20] & Yes & Foreign key \\
ADM_STU_ID & Char [20] & No & \\
ADM_Email & Char[50] & Yes & \\
ADM_Tel & Char [20] & Yes & \\
\hline
\end{tabular}

education curriculum management system based on the Internet of Things are shown in Table 5.

After logging into the system as an administrator from the background, we conducted statistics and data analysis on the physical education teacher's class schedule. The test results are shown in Figure 5.

It can be seen from Figure 5 that the physical education teacher of the university has set up four kinds of physical education classes for basketball, football, badminton, and volleyball for the students of the major. The course time is arranged in two time periods in the morning and two in the afternoon. Among them, the two time periods of $8: 30-10$ : 30 in the morning and 15:00-17:00 in the afternoon have the largest number of classes. They are the most popular among teachers and students. The plan for one year lies in spring. The daily plan lies in the morning. 8:30 in the morning is when the students are more awake. Physical exercise at this time is beneficial to physical and mental health and promotes blood circulation. 15:00-17:00 in the afternoon is not the hottest of the day. Studying at this time will make the students feel drowsy, so it is more suitable for students to do physical activities at this time, so that the brain will wake up, which is conducive to studying at night. Therefore we can draw a conclusion: physical education teachers can try their best to arrange physical education courses before 10 in the morning or after 3 in the afternoon, which is good for students and teachers.

4.2. Student Selection Data. We let a total of 600 students from 4 grades of civil engineering majors use this physical education curriculum management system to simulate their favorite physical education courses. We analyzed the results of simulated course selection and plotted them into statistical graphs. The statistical results are shown in Figure 6.

It can be seen from Figure 6 that there is a big difference between the type of course selection and gender. More than $60 \%$ of boys have a soft spot for basketball and football, and they believe that the confrontation between basketball and football is more intense and can test the basic body of students. Only a small number of boys choose badminton and volleyball, thinking that these two sports are more relaxed and interesting and can cultivate sentiment. For girls, it is the opposite of the boys' choice of courses. They think that girls' choice of sports, such as basketball and football, which are relatively stronger in physical confrontation, will be more likely to cause injuries and bring serious consequences,
TABLE 5: System development environment and development tools.

\begin{tabular}{lc}
\hline $\mathrm{Cpu}$ & Intel Core I5-7300u \\
\hline $\mathrm{Gpu}$ & Geforce Gtx 1060ti \\
Operating system & Windows 10 professional edition 64 bit \\
Ram & $8 \mathrm{gb}$ \\
Jre version & 1.8 \\
Development platform & Eclipse \\
Server & Tomcat8.5 \\
\hline
\end{tabular}

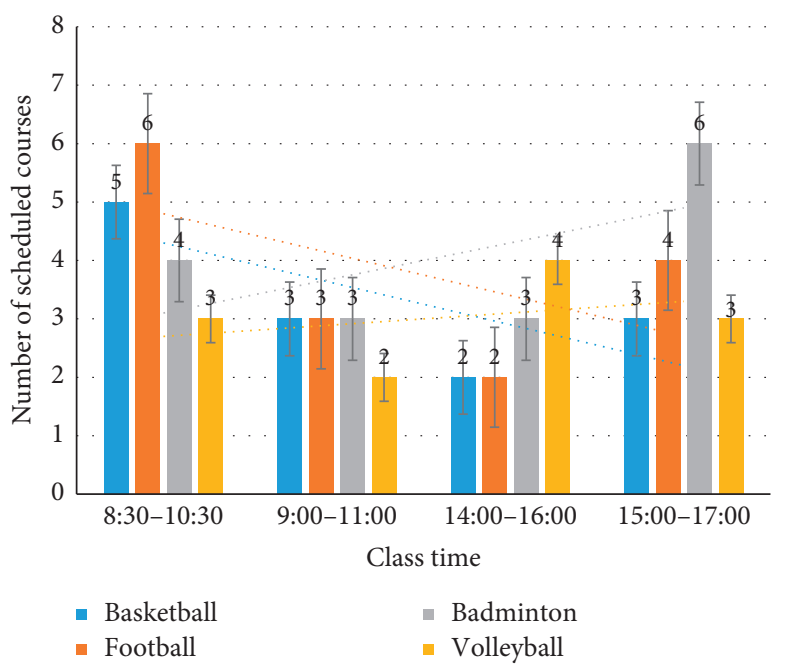

FIGURE 5: The number of physical education courses arranged in different time periods.

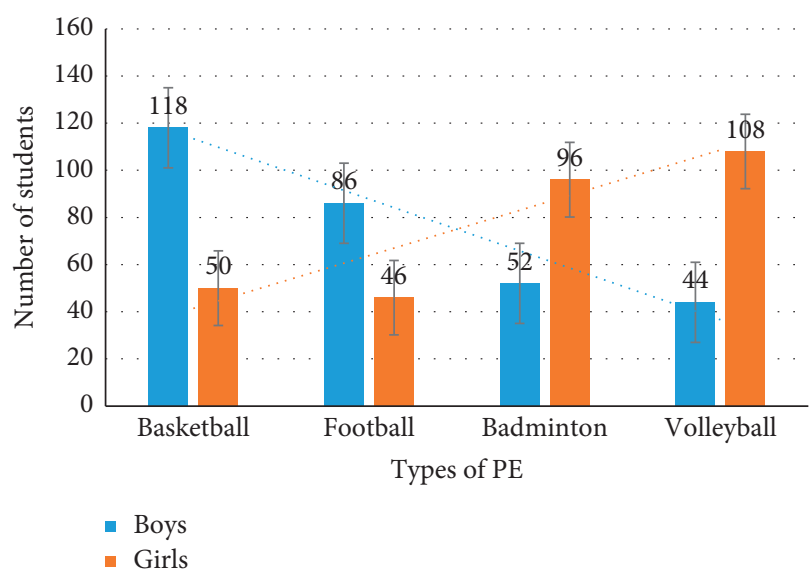

FIgURE 6: Statistics of student selection results.

so they are more willing to choose a relatively gentle physical education curriculum.

4.3. System Performance Analysis. In this system test, statistics are made on the sign-in rates of physical education courses of students of different grades, and they have been checked with the actual sign-in tables in the physical education class. The statistical results are shown in Figure 7. 


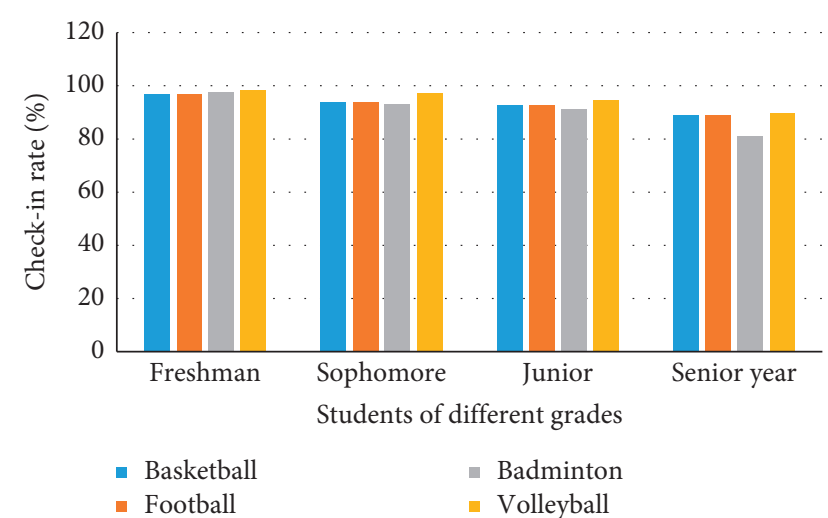

FIgURE 7: Sign-in rate of various physical education courses.

It can be seen from Figure 7 that the sign-in rate of all physical education courses for freshmen is relatively high, because freshmen just enter the university and do not know the various rules and regulations of the school, so the sign-in rate is relatively higher than that of students in other grades. Among all physical education courses, volleyball courses have the highest sign-in rate. It can be seen that volleyball teachers are more stringent in management than other physical education teachers. In summary, a conclusion can be drawn: the administrator module of the system has good test performance, which is beneficial to help college physical education teachers manage the arrangements of students and courses. The administrator function module design is also reasonable and easy to operate.

\section{Conclusions}

The design of this system optimizes the location sign-in of students' physical education class, which increases the accuracy of location sign-in by $2 \%-3 \%$. On the premise that the server does not crash, the goal of nearly 600 people choosing physical education class at the same time has been achieved. With the continuous development of the Internet of Things technology, colleges and universities will have more and more demands for the management system of physical education courses, and the performance requirements of the system will also increase. This paper designs a college curriculum management system based on the Internet of Things to solve the problems in traditional management and improve the level of college physical education curriculum management. It is an attempt to apply the Internet of Things to college physical education curriculum management. It can be applied to modern teaching and public places. However, as the Internet of Things technology industry continues to grow, and the content of physical education courses continues to be enriched, more management methods are needed to suit them. Therefore, further in-depth research is needed by related technology developers.

\section{Data Availability}

The data that support the findings of this study are available from the corresponding author upon reasonable request.

\section{Conflicts of Interest}

The authors declare that they have no conflicts of interest.

\section{References}

[1] L.-H. Shih, Y.-T. Lee, and F. Huarng, "Creating customer value for product service systems by incorporating internet of things technology," Sustainability, vol. 8, no. 12, Article ID 1217, 2016.

[2] V. Fratto, M. G. Sava, and G. J. Krivacek, "The impact of an online homework management system on student performance and course satisfaction in introductory financial accounting," International Journal of Information and Communication Technology Education, vol. 12, no. 3, pp. 76-87, 2016.

[3] S. Yeo, "Course quality management based on monitoring by students at a medical school," Korean Journal of Medical Education, vol. 30, no. 2, pp. 141-152, 2018.

[4] E. Coatanea, R. Roca, H. Mokhtarian, F. Mokammel, and K. Ikkala, "A conceptual modeling and simulation framework for system design," Computing in Science \& Engineering, vol. 18 , no. 4, pp. 42-52, 2016.

[5] W. U. Zhao-Hui, "Research on the application of internet of things technology to digital museum construction," Acta Geoscientica Sinica, vol. 38, no. 2, pp. 293-298, 2017.

[6] F. Victoria, G. S. Magda, and J. K. Gregory, "The impact of an online homework management system on student performance and course satisfaction in introductory financial accounting," International Journal of Information and Communication Technology Education: An Official Pubblication of the Information Resources Management Association, vol. 12, no. 3, pp. 76-87, 2016.

[7] U. Hüseyin, T. Murat, and P. Y. Ezgi, "The effects of the authentic learning approach with a course management system (moodle) on students mathematics success and online authentic learning self-efficacy," Educational Research and Reviews, vol. 15, no. 11, pp. 679-689, 2020.

[8] N. Ayman and A. M. Abualkishik, "Predictive factors for the intention to adopt a mobile blackboard course management system: the case study of university of hail in Saudi arabia," Indian Journal of Science and Technology, vol. 12, no. 19, pp. 1-12, 2019.

[9] M. Barcomb and W. Cardoso, "Rock or Lock? Gamifying an online course management system for pronunciation instruction: focus on English/r/and/l/," CALICO Journal, vol. 37, no. 2, pp. 127-147, 2019.

[10] E. N. Ekwonwune and D. C. Edebatu, "Design and implementation of an online course management system," Journal of Software Engineering and Applications, vol. 12, no. 2, pp. 21-33, 2019.

[11] K. Ibraheem Arif, "Building an online course management system for Iraqi education colleges," Indian Journal of Science and Technology, vol. 11, no. 7, pp. 1-6, 2018.

[12] S. Zhao, S. Li, and Y. Yao, "Blockchain enabled industrial internet of things technology," IEEE Transactions on Computational Social Systems, vol. 6, no. 6, pp. 1442-1453, 2019.

[13] L. W. Wardana, "Paper airplane and talking stick learning methods to increase students understanding about management information system courses," IOSR Journal of Business and Management, vol. 18, no. 9, pp. 164-169, 2016.

[14] S. Siekmann, "Which web course management system is right for me? A comparison of WebCT 3.1 and blackboard 5.0," CALICO Journal, vol. 18, no. 3, pp. 590-617, 2017. 
[15] C. Kang, D. Chen, X. Sun et al., "Container Ocean-transportation System Design with the factors of demand fluctuation and choice inertia of shippers," Transportation Research Part E Logistics and Transportation Review, vol. 95, pp. 267281, 2016.

[16] P. C. Smith and W. Yip, "The economics of health system design," Oxford Review of Economic Policy, vol. 32, no. 1, pp. 21-40, 2016.

[17] Q. C. Curran, D. Allaire, and K. E. Willcox, "Sensitivity analysis methods for mitigating uncertainty in engineering system design," Systems Engineering, vol. 21, no. 3, pp. 191-209, 2018.

[18] M. Arsalan, S. K. Susmita, R. Anand, and N. K. Jha, "Wearable medical sensor-based system design: a survey," IEEE Transactions on Multi-Scale Computing Systems, vol. 3, no. 2, pp. 124-138, 2017.

[19] W. K. Hocking, "System design, signal-processing procedures, and preliminary results for the Canadian (London, Ontario) VHF atmospheric radar," Radio Science, vol. 32, no. 2, pp. 687-706, 2016.

[20] C. Kim, Y. H. Yun, K. Kim, and J.-Y. Seol, "Introduction to QAM-FBMC: from waveform optimization to system design," IEEE Communications Magazine, vol. 54, no. 11, pp. 66-73, 2016.

[21] F. Miramirkhani, O. Narmanlioglu, M. Uysal, and E. Panayirci, "A mobile channel model for VLC and application to adaptive system design," IEEE Communications Letters, vol. 21, no. 5, pp. 1035-1038, 2017.

[22] A.-A. J. Diego, G.-G. Gabriel, G. Francesc et al., "Fuzzy logicbased energy management system design for residential gridconnected microgrids," IEEE Transactions on Smart Grid, vol. 9, no. 2, pp. 530-543, 2016.

[23] Z. U. Bayrak, G. Bayrak, M. T. Ozdemir, M. T. Gencoglu, and M. Cebeci, "A low-cost power management system design for residential hydrogen \& solar energy based power plants," International Journal of Hydrogen Energy, vol. 41, no. 29, pp. 12569-12581, 2016.

[24] P. Bhore, S. Joshi, and N. Jayakumar, "Handling anomalies in the system design: a unique methodology and solution," International Journal of Emerging Trends \& Technology in Computer Science, vol. 5, no. 2, pp. 409-413, 2017.

[25] S. Tripakis, "Compositionality in the science of system design," Proceedings of the IEEE, vol. 104, no. 5, pp. 960-972, 2016.

[26] Z. Lv, "Virtual reality in the context of internet of things," Neural Computing and Applications, vol. 32, pp. 1-10, 2019.

[27] H. Tao, W. Zhao, R. Liu, and M. Kadoch, "Space-air-ground IoT network and related key technologies," IEEE Wireless Communications, vol. 27, 2019.

[28] M. Ali, L. T. Jung, A.-H. Abdel-Aty, M. Y. Abubakar, M. Elhoseny, and I. Ali, "Semantic-k-NN algorithm: an enhanced version of traditional k-NN algorithm," Expert Systems with Applications, vol. 151, Article ID 113374, 2020.

[29] K. Kaur, S. Guo, M. Chen, and D. Rawat, "Transfer learning for 5g-aided industrial internet of things," IEEE Transactions on Industrial Informatics, vol. 2021, p. 1, 2021. 